\title{
The Role of Soluble Subtype of the Receptor for Advanced Glycation End Product (sRAGE) in Rheumatoid Arthrirtis Disease Activity and Treatment Follow-up
}

\author{
DOAA M.A. EL-ZOGHBY, M.D. ${ }^{1}$; NEHAL EL-FAWY MAHMOUD, M.D. ${ }^{2}$; \\ NERMIN H. EL-GHARBAWY, M.D. ${ }^{3}$ and SAFAA M. ABD EL-RAHMAN, M.D. ${ }^{4}$ \\ The Departments of Clinical Pathology ${ }^{1}$, Internal Medicine, Allergy \& Immunology ${ }^{2}$, \\ Physical Medicine, Rheumatology \& Rehabilitation ${ }^{3}$ and Medical Microbiology \& Immunology ${ }^{4}$, \\ Faculty of Medicine, Ain Shams University
}

\begin{abstract}
Background: Advanced Glycation End products (AGEs) are products of a non-enzymatic reaction between sugars and free amino groups of protein. They are one of several molecules that play a role in the pathogenesis of Rheumatoid Arthritis (RA). A soluble subtype of the receptor for advanced glycation end products (sRAGE) which can be measured in serum has been gaining interest for its contribution in RA.
\end{abstract}

Aim of Study: The aim of this work is to assess the role of sRAGE in monitoring disease activity, disease treatment and follow-up.

Subjects and Methods: This retrospective case-control study was conducted on (50) patients with rheumatoid arthritis (group 1) and their age and sex matching (30) healthy controls (group 2). All subjects recruited in our study were subjected to measurement of serum soluble subtype of the receptor for advanced glycation end products (sRAGE) by ELISA technique.

Results: Results of our study shows significant statistical decrease in serum sRAGE levels among different studied disease activity score 28 (DAS28) 28 grades (H:6.02, $p<0.05$ ). The inverse association between serum sRAGE and DAS28 is confirmed by the highly significant negative correlation between them $(r:-0.397, p<0.01)$. No significant statistical difference is seen in serum sRAGE between patients on treatment with methotrexate and those not treated with it $(\mathrm{Z}$ : $0.39, p>0.05$ ).

Conclusion: Serum sRAGE level is strongly related to the disease activity in rheumatoid arthritis with its serum levels being lower in active disease. Our study could not prove its role in disease treatment follow-up.

Key Words: Rheumatoid arthritis - sRAGE - Disease activity - ELISA.

Correspondence to: Dr. Doaa M.A. El-Zoghby, The Department of Clinical Pathology, Faculty of Medicine, Ain Shams University

\section{Introduction}

RHEUMATOID Arthritis (RA) is mediated by macrophages, lymphocytes and synovial fibroblasts, causing chronic inflammatory synovitis with the resultant destruction of bone and cartilage. Several molecules play a role in the pathogenesis of RA [1].

One of these molecules is Advanced Glycation End products (AGEs) which are products of a nonenzymatic reaction between sugars and free amino groups of protein. AGE accumulation in different tissues can lead to damage through alterations in tissue protein structure and function. A specific receptor (RAGE) is needed to conduct this action [2]

The receptor for advanced glycation end products (RAGE) is a multi-ligand member of the immunoglobulin superfamily. RAGE is expressed on $T$ cells and macrophages within synovial tissues of RA patients, as well as on synovial lining layer of fibroblasts [3].

A soluble subtype of the RAGE protein (sRAGE) is composed of only an extracellular domain, lacking the part that transfers a signal into the cell. This sRAGE competes with RAGE for ligand binding, thus blocking the damaging effect of AGE on the tissues. sRAGE was found to significantly reduce synovial inflammation, as well as cartilage and bone destruction, when it was used to treat collagen-induced arthritis in mice [1] .

Our aim was to measure the levels of sRAGE in patients with RA in relation to their disease activity score (DAS-28) [4] and in comparison to 
healthy control subjects, and to explore its possible role in treatment follow-up.

\section{Subjects and Methods}

Subjects:

This case-control study was conducted on fifty (50) patients (46 females and 4 males) with mean age 27 (22-32) years old suffering from rheumatoid arthritis for 4 (2-9.5) years (Group 1) recruited from Rheumatology Clinic, Internal Medicine Department, Ain Shams University Hospitals, Cairo, Egypt between March and October 2018. In addition to thirty (30) healthy age and sex matched subjects serving as healthy control group (Group 2). Rheumatoid arthritis was diagnosed based on the American College of Rheumatology criteria for RA [5]. Disease activity was assessed using Disease Activity Score 28 (DAS28) [4].

Exclusion criteria included patients older than 75 years, pregnancy, renal impairment (serum creatinine $>140 \mathrm{tmol} / \mathrm{L}$ ), surgery, myocardial infarction or sepsis in the past three months to exclude other factors that may influence sRAGE levels.

After taking an informed oral consent, all individuals included in the study were subjected to full history taking, throughofull clinical examination, ESR measurements (for patients' group only), in addition to the assay of serum sRAGE by ELISA technique. The procedures applied in this study were approved by The Ethical Committee of Human Experimentation of Ain Shams University, and are in accordance with the Helsiniki Declaration of 1975.

Sampling: Five milliliters of venous blood were collected under complete aseptic precautions; two milliliters were placed in ESR tubes, while the rest was evacuated in plain test tubes. The serum was separated by centrifugation (1000xg for 15 minutes) and stored at $-20^{\circ} \mathrm{C}$ for subsequent assay of sRAGE. Haemolysed samples were discarded. Repeated freezing and thawing was avoided.

\section{Analytical methods:}

ESR assay was performed using Wintrobes method. sRAGE assay was done using the commercially available Enzyme-Linked Immunosorbent Assay (ELISA) kit supplied by R \& D Systems (USA \& Canada|R \& D Systems, Inc. 614 McKinley Place NE, Minneapolis, MN 55413, USA). All procedures were carried out according to the instructions of the manufacturers. Each standard and serum sample was analyzed twice and the mean value was used in all subsequent analyses.
The intra-assay and interassay variation coefficients were less than $10 \%$.

\section{Assay of sRAGE:}

This assay employs the quantitative sandwich enzyme immunoassay technique. A monoclonal antibody specific for human sRAGE (extracellular domain) has been pre-coated onto a microplate. Standards and samples are pipetted into the wells and any sRAGE present is bound by the immobilized antibody. After washing away any unbound substances, an enzyme-linked polyclonal antibody specific for human sRAGE (extracellular domain) is added to the wells. Following a wash to remove any unbound antibody-enzyme reagent, a substrate solution is added to the wells and color develops in proportion to the amount of sRAGE bound in the initial step. The color development is stopped and the intensity of the color is measured.

\section{Calculation of results:}

Construction of a standard curve is done by plotting the mean absorbance for each standard on the $y$-axis against the concentration on the $\mathrm{x}$-axis and drawing a best fit curve through the points on the graph. If samples have been diluted, the concentration read from the standard curve must be multiplied by the dilution factor.

\section{Statistical methods:}

Statistical analysis was performed using statistical software program IBM SPSS statistics (V. 25.0, IBM Corp., USA, 2017-2018). The nonparametric quantitative data were expressed as median and interquartile range. Comparative statistics were done using Kruskal Wallis test and Wilcoxon rank sum test. Correlation analysis was performed using Spearman's rank correlation coefficient (rs). Forward multiple linear regression analysis was performed with sRAGE levels as the dependent variable and those determinants that correlated in the univariate analysis with $p<0.05$ as independent variables. $p<0.05$ was considered significant and $p<0.01$ was considered highly significant.

\section{Results}

The results obtained in the study are shown in (Tables 1-8).

Table (1) shows descriptive data in rheumatoid arthritis patients (Group 1) and control (Group 2) for age, sex, Disease Duration (DD) and sRAGE described as median and interquartile range for non parametric data. Among the fifty patients included in the study, twelve patients were seron- 
egative for Rheumatoid Factor (RF) with sRAGE ranging between $(90-260 \mathrm{pg} / \mathrm{mL})$.

Table (1): Descriptive data for Group 1 (cases) and Group 2 (control).

\begin{tabular}{lcc}
\hline Parameter & $\begin{array}{c}\text { Cases }(\mathrm{n}=50) \\
\text { Median }\left(\mathrm{Q} 1-\mathrm{Q}_{3}\right)\end{array}$ & $\begin{array}{c}\text { Control }(\mathrm{n}=30) \\
\text { Median }\left(\mathrm{Q} 1-\mathrm{Q}_{3}\right)\end{array}$ \\
\hline Age (years) & $27(22-32)$ & $43(36.5-50)$ \\
Male (n) & 4 & 18 \\
Female (n) & 46 & 12 \\
DD (years) & $4(2-9.5)$ & \\
sRAGE $(\mathrm{pg} / \mathrm{mL})$ & $120(90-200)$ & $170(100-225)$ \\
\hline
\end{tabular}

Descriptive and comparative statistics in (Table 2) for different studied parameters among different disease activity grades (A, B \& C) using DAS 28 for RA activity evaluation. Grade A (patient in remission whom DAS $28<2.6$ ), Grade B patients with low active disease in whom DAS 28 ranged (2.6-3.2) and Grade C (patients with moderate to severe disease activity whom DAS 28 was 3.2-5.1 and $>5.1$ respectively). Serum sRAGE levels showed a statistically significant decrease in its level among different disease Grades A, B and C of rheumatoid arthritis (H: 6.02, $p<0.05$ ).

Table (2): Descriptive and comparative statistics of different studied parameters using Kruskal Wallis test among Grades A, B and C.

\begin{tabular}{|c|c|c|c|c|c|}
\hline \multirow[b]{2}{*}{ Parameter } & \multicolumn{3}{|c|}{ Grades } & \multirow[b]{2}{*}{$\mathrm{H}$} & \multirow[b]{2}{*}{$p$} \\
\hline & $\begin{array}{c}A(n=10) \\
\text { Median }\left(Q 1-Q_{3}\right)\end{array}$ & $\begin{array}{c}\mathrm{B}(\mathrm{n}=10) \\
\text { Median }\left(\mathrm{Q} 1-\mathrm{Q}_{3}\right)\end{array}$ & $\begin{array}{c}\mathrm{C}(\mathrm{n}=30) \\
\text { Median }\left(\mathrm{Q} 1-\mathrm{Q}_{3}\right)\end{array}$ & & \\
\hline DD (years) & $6.5(4-13.5)$ & $4 \pm(1.75-22.5)$ & $4(1-8)$ & 3.29 & $>0.05$ \\
\hline sRAGE (pg/mL) & $165(145-192.5)$ & $200(175-260)$ & $125(78-200)$ & 6.02 & $<0.05$ \\
\hline ESR (mm/hour) & $27.5(15.3-37.5)$ & $40(13.5-568)$ & $36(20-50)$ & 2.96 & $>0.05$ \\
\hline $\begin{array}{l}p>0.05 \text { is non signi } \\
p<0.05 \text { is significan } \\
\text { DD: Disease Durati }\end{array}$ & & $\begin{array}{l}\text { Grade A: Disease in } \\
\text { Grade B: Disease lo } \\
\text { Grade C: Disease m }\end{array}$ & $\begin{array}{l}\text { emission. } \\
\text { activity. } \\
\text { derate to severe acti }\end{array}$ & & \\
\hline
\end{tabular}

Comparison between Grade A and B, B and C and $\mathrm{A}$ and $\mathrm{C}$ in (Table 3), sRAGE serum levels show a statistically significant difference between Grades A and B and B and C (H:1.97 and 2.19 respectively) and $p<0.05$. While sRAGE shows a non significant statistical difference between grade A and $\mathrm{C}$ (H: $1.006, p>0.05)$.

Table (3): Comparative statistics between disease activity grades $\mathrm{A} / \mathrm{B}, \mathrm{A} / \mathrm{C}$ and $\mathrm{B} / \mathrm{C}$ as regards different studied parameters using Wilcoxon Rank Sum test.

\begin{tabular}{|c|c|c|c|c|c|c|}
\hline \multirow{2}{*}{ Parameter } & \multicolumn{2}{|c|}{$\begin{array}{c}\text { Grades } \\
\text { (A \& B) }\end{array}$} & \multicolumn{2}{|c|}{$\begin{array}{c}\text { Grades } \\
(\mathrm{A} \& \mathrm{C})\end{array}$} & \multicolumn{2}{|c|}{$\begin{array}{c}\text { Grades } \\
(B \& C)\end{array}$} \\
\hline & Z & $p$ & Z & $p$ & Z & $p$ \\
\hline DD (years) & 0.363 & $>0.05$ & 1.74 & $>0.05$ & 1.014 & $>0.05$ \\
\hline ESR (mm/hour) & 1.08 & $>0.05$ & 1.72 & $>0.05$ & 0.438 & $>0.05$ \\
\hline sRAGE (pg/mL) & 1.972 & $<0.05$ & 1.006 & $>0.05$ & 2.197 & $<0.05$ \\
\hline
\end{tabular}

$p>0.05$ is non significant. $p<0.05$ is significant. DD: Disease Duration.

Grade A: Disease in remission. Grade B: Disease low activity. Grade C: Disease moderate to severe activity.

Comparative statistics shown in (Table 4) between different studied parameters and effect of treatment or not with methotrexate shows a highly significant statistical difference in ESR (Z:3.07, $p<0.01)$. Meanwhile, a significant statistical difference is seen in DAS28 $(\mathrm{Z}: 2.021, p<0.05)$. On the other hand, sRAGE shows no statistical difference between patients treated or not with methotrexate (Z:0.39, $p>0.05)$.
Table (4): Comparative statistics for effect of treatment or not with methotrexate as regards different studied parameters using Wilcoxon Rank Sum test.

\begin{tabular}{|c|c|c|c|c|}
\hline Parameter & \multicolumn{2}{|c|}{ Treatment } & Z & $p$ \\
\hline DD (years) & $\begin{array}{l}\text { Negative } \\
\text { Positive }\end{array}$ & $\begin{array}{l}(\mathrm{n}: 24) \\
(\mathrm{n}: 26)\end{array}$ & 1.25 & $>0.05$ \\
\hline ESR (mm/hour) & $\begin{array}{l}\text { Negative } \\
\text { Positive }\end{array}$ & $\begin{array}{l}(\mathrm{n}: 24) \\
(\mathrm{n}: 26)\end{array}$ & 3.07 & $<0.01$ \\
\hline DAS 28 & $\begin{array}{l}\text { Negative } \\
\text { Positive }\end{array}$ & $\begin{array}{l}(\mathrm{n}: 24) \\
(\mathrm{n}: 26)\end{array}$ & 2.021 & $<0.05$ \\
\hline sRAGE (pg/mL) & $\begin{array}{l}\text { Negative } \\
\text { Positive }\end{array}$ & $\begin{array}{l}(\mathrm{n}: 24) \\
(\mathrm{n}: 26)\end{array}$ & 0.39 & $>0.05$ \\
\hline
\end{tabular}

Table (5) shows a highly statistical significant association between genders of the patients included in the study and occurrence of the disease $(p<0.01)$.

Table (5): Comparative statistics between cases (Group 1) and control (Group 2) as regards sex using Pearson Chi-Square test.

\begin{tabular}{cllll}
\hline Gender & Cases & Control & $\chi^{2}$ & $p$ \\
\hline$F:$ & & & & \\
$\mathrm{N}$ & 46 & 12 & 25.43 & $<0.01$ \\
$\%$ & $92 \%$ & $40 \%$ & & \\
$M:$ & & & & \\
$\mathrm{N}$ & 4 & 18 & & \\
$\%$ & $8 \%$ & $60 \%$ & & \\
\hline
\end{tabular}

$p<0.01$ is highly significant. 
DAS28 shows a highly significant negative statistical correlation with sRAGE $(r: 0.397, p<$ 0.01 ) as seen in (Table 6).

Table (6): Statistical correlation between RAGE and different studied parameters using Ranked Spearman correlation test.

\begin{tabular}{lll}
\hline & \multicolumn{2}{c}{ sRAGE } \\
\cline { 2 - 3 } Parameter & \multicolumn{1}{c}{$r$} & $p$ \\
\hline Age (years) & 0.153 & $>0.05$ \\
DD (years) & 0.037 & $>0.05$ \\
ESR (mm/hour) & 0.14 & $>0.05$ \\
DAS28 & -0.397 & $<0.01$ \\
\hline
\end{tabular}

$p>0.05$ is non significant.

$p<0.01$ is highly significant.

$p<0.01$ is highly significant.

DD : Disease Duration.

DAS 28: Disease Activity Score 28.

Multiple linear regression analysis (Tables 7,8) indicated that only the DAS 28 levels were dependent predictors of sRAGE levels in RA. The regression equation of sRAGE levels was $\mathrm{Y}=\mathrm{a}+\mathrm{b} 1 \mathrm{X} 1$ $+\mathrm{b} 2 \mathrm{X} 2+\mathrm{b} 3 \mathrm{X} 3+\operatorname{bnxn}(\mathrm{Y}$ is the dependent variable; $a$ is the constant; $b 1$ regression coefficient for independent variable $1, \mathrm{X} 1$ is the result of the independent variable 1 . While $\mathrm{b} 2$ is regression coefficient for independent variable $2, \mathrm{X}^{2}$ is the result of the independent variable 2$)(p<0.05)$.

Table (7): Logistic stepwise multi-regression analysis with dependent variable is sRAGE (model 1).

\begin{tabular}{llcll}
\hline Parameter & Reg. Coef. & $t$ & $p$ & F-ratio \\
\hline (Constant) & 320.425 & 3.079 & $<0.01$ & \\
Age (years) & -0.104 & -0.045 & $>0.05$ & \\
DD (years) & -1.73 & -0.515 & $>0.05$ & \\
ESR (mm/hour) & 1.943 & 1.913 & $>0.05$ & \\
DAS28 & -50.166 & -2.613 & $<0.05$ &
\end{tabular}

$1.989>0.05$

$p>0.05$ is non significant.

$p<0.05$ is significant.

$p<0.01$ is highly significant

DD : Disease Duration.

DAS 28: Disease Activity Score 28

Table (8): Logistic stepwise multi-regression analysis with dependent variable is sRAGE (model 2).

\begin{tabular}{lccccc}
\hline Parameter & Reg. Coef. & $t$ & $p$ & F-ratio & $p$ \\
\hline (Constant) & 298.54 & 4.49 & $<0.01$ & & \\
ESR (mm/hour) & 1.75 & 1.88 & $>0.02$ & \\
DAS28 & -46.65 & -2.56 & $<0.05$ &
\end{tabular}

$3.813<0.05$

$p>0.05$ is non significant.

$p<0.05$ is significant.

$p<0.01$ is highly significant

DAS 28: Disease Activity Score 28.

\section{Discussion}

Rheumatoid Arthritis (RA) is a chronic inflammatory disease leading to bone and cartilage destruction in addition to extra-articular complications as atherosclerotic vascular disease and premature mortality [6]. These vascular events are attributed to altered vascular reactivity due to endothelial dysfunction, consequent to vascular damage [7] .

Soluble receptor for advanced glycation end products (sRAGE) is an anti-inflammatory factor that mediates the pro-inflammatory effects of high mobility group box chromosomal protein 1 (HMGB-1). HMGB-1 is implicated in cell signaling by synergizing with DNA CpG motifs [8]. Therefore, sRAGE are considered as inducers, sensors, and mediators of the inflammatory processes [9]. Ctruncated sRAGE lacks the transmembrane and cytosolic domains of the full-length receptor and can prevent pro-inflammatory effects of RAGE signaling by acting as a decoy [6]. This action can be mediated by removal/neutralization of circulating ligands and raises the possibility of using plasma sRAGE as a promising therapeutic target to prevent multiple diseases including RA [10]

From this prospect, the present study investigates the association between sRAGE and the activity of RA in fifty (50) patients (Group 1) in comparison to thirty (30) controls (Group 2) and tries to find its possible role in RA treatment follow-up.

Our study revealed that sRAGE levels vary significantly with the Grade A patients (disease in remission), Grade B (disease low activity) and grade $\mathrm{C}$ (disease moderate to severe activity). Same data were published by Pullerits et al., [1] and Chan et al., [6] who found associations of sRAGE with clinical inflammatory factors, complications, and cardiovascular risk factors in established RA patients and the blood levels of sRAGE were significantly lower in RA patients than in healthy controls $[\mathbf{1 , 6 ]}$

The levels of sRAGE significantly varied between Grades A and B and between Grades B and $\mathrm{C}$ of disease activity and these changes are accompanied by non significant changes in ESR. Levels of sRAGE are lower in Grades C with moderate to severe disease activity in comparison to Grade B with low activity of the disease and in Grade A with patients are in remission. Zhang et al., [8] agreed in their study that the blood levels of sRAGE were significantly lower in RA patients than in healthy controls and synovial fluid from RA patients treated with Disease-Modifying Anti-Rheumatic 
Drug (DMARDs) contained higher sRAGE concentrations compared with that from patients not treated with DMARDs, which shows compromised inflammatory control in active RA. They proposed that the sRAGE attenuated rheumatoid inflammation through reciprocal regulation of $\mathrm{T}$ helper and T.reg cells [8]. Similarly Mokbail et al., [10] reported the decrease in the level of serum sRAGE in Egyptian patients with rheumatoid arthritis and its association with markers of disease activity. They suggested that sRAGE may block the ligand-RAGE interaction on the cell surface by directly binding leukocyte (32-integrin Mac-1 and thereby decreasing influx of inflammatory cells into the joint cavity, functioning as an immune surveillance mechanism. Lower levels of sRAGE detected in RA patients might thus increase the propensity towards inflammation since RAGE ligands have better access to cell membrane-bound receptor, the binding of which leads to the activation of inflammatory pathways [10].

The highly significant negative correlation between sRAGE and DAS28 empowers our findings to the relation between serum levels of sRAGE and scoring systems of rheumatoid arthritis disease activity and introduces SRAGE as an excellent target for monitoring improved disease activity during therapy. Results of our study supports the independent role of sRAGE in follow-up of activity in RA patients on treatment as the sRAGE is non significantly changed in patients either treated or not with methotrexate which gives it a superior benefit over both DAS28 and ESR levels that are significantly changed accordingly with methotrexate treatment. Several recent studies aimed at defining this new prospect for sRAGE. In their study, Rowan et al., [11] has reviewed the pathways leading to formation of Advanced Glycation End products (AGE), largely from sugars and glycolytic intermediates, and discussed detoxification of AGE precursors, including the glyoxalase system and DJ-1/Park7 deglycase. They reported that extracellular AGE also activates RAGE signaling, leading to oxidative stress, inflammation, and leukostasis in diabetic complications such as diabetic retinopathy. Their study recommended diminishing glycative stress by: Plant-derived polyphenols as AGE inhibitors and glyoxalase inducers; improved dietary patterns, particularly Mediterranean and low glycemic diets; and enhancing proteolytic capacities of the ubiquitin-proteasome and autophagy pathways that are involved in cellular clearing of AGEs [11]

The stepwise multi-regression analysis for our data highlights the relation between sRAGE as dependant variable that is significantly predicted only by disease activity score. Similarly, regression analysis study for sRAGE and disease duration, rheumatoid factor, C-Reactive Protein (CRP) and sRAGE gene polymorphism done by Mokbail et al., [10] found only CRP and gene polymorphism as significant predictors for sRAGE [10]. Moreover, Chan et al., [4] reported C-reactive protein, cardiovascular disease, high-density lipoprotein, and rheumatoid factor to be significant predictors for sRAGE in their linear regression analysis [4].

The presence of 12 out of 50 (24\%) RA patients with seronegative rheumatoid factor is a worth note finding that adds a possible superior role for sRAGE above the conventional rheumatoid factor for monitoring disease activity which needs to be further studied on a larger scale of patients. A similar finding was reported by Mokbail et al., [10] in their work with 9 RA patients out of 31 enrolled in their study $(27.3 \%)$ had rheumatoid factor negative not corresponding to the disease activity or sRAGE level [10]

\section{Conclusion:}

sRAGE is strongly related to the disease activity in rheumatoid arthritis with its serum levels lowered in active disease. Unfortunately, we didn't find a relation between sRAGE and effectiveness of treatment. This may need more researches with long follow-up periods on a larger study sample size.

\section{Conflict of interest:}

All authors declare that they have no financial or institutional interests related to this manuscript.

\section{References}

1- PULLERITS R., BOKAREWA M., DAHLBERG L. and TARKOWSKI A.: Decreased levels of soluble receptor for advanced glycation end products in patients with rheumatoid arthritis indicating deficient inflammatory control. Arthritis Res. Ther., 7 (4): R817-24, 2005.

2- DRINDA S., FRANKE S., RÜSTER M., PETROW P., PULLIG O., STEIN G., et al.: Identification of the receptor for advanced glycation end products in synovial tissue of patients with rheumatoid arthritis. Rheumatol. Int., 25 (6): 411-3, 2005.

3- HOU F.F., JIANG J.P., GUO J.Q., WANG G.B., ZHANG X., STERN D.M., et al.: Receptor for advanced glycation end products on human synovial fibroblasts: Role in the pathogenesis of dialysis-related amyloidosis. J. Am. Soc. Nephrol., 13: 1296-306, 2002.

4- ANDERSON J.K., ZIMMERMAN L., CAPLAN L. and MICHAUD K.: Measures of rheumatoid arthritis disease activity: Patient (PtGA) and Provider (PrGA) Global Assessment of Disease Activity, Disease Activity Score (DAS) and Disease Activity Score with 28-Joint Counts (DAS28), Simplified Disease Activity Index (SDAI), Clinical Disease Activity Index (CDAI), Patient Activity 
Score (PAS) and Patient Activity Score-II (PASII), Routine Assessment of Patient Index Data (RAPID), Rheumatoid Arthritis Disease Activity Index (RADAI) and Rheumatoid Arthritis Disease Activity Index-5 (RADAI-5), Chronic Arthritis Systemic Index (CASI), Patient-Based Disease Activity Score With ESR (PDAS1) and Patient-Based Disease Activity Score without ESR (PDAS2), and Mean Overall Index for Rheumatoid Arthritis (MOI-RA). Arthritis Care Res (Hoboken), 63 Suppl 11: S14-36, 2011.

5- ALETAHA D., NEOGI T., SILMAN A.J., FUNOVITS J., FELSON D.T., BINGHAM C.O. $3^{\text {rd }}$, et al.: Rheumatoid arthritis classification criteria: An American College of Rheumatology/European League Against Rheumatism collaborative initiative. Arthritis Rheum., 62 (9): 256981, 2010.

6- CHEN Y.S., YAN W., GECZY C.L., BROWN M.A. and THOMAS R.: Serum levels of soluble receptor for advanced glycation end products and of S 100 proteins are associated with inflammatory, autoantibody, and classical risk markers of joint and vascular damage in rheumatoid arthritis. Arthritis Res. Ther., 11 (2): R39, 2009.

7- AÇIKALIN Ö., BÖLÜKBAŞI HATIP F.F., TAN R.F. and HATIP-AL-KHATIB I.: Effect of Angiotensin-(1-7) on
Aortic Response, TNF-a, IL-1 3 and Receptor for Advanced Glycation Endproduct in Rat's Adjuvant-Induced Arthritis. Pharmacology, 97: 207-17, 2016.

8- ZHANG D.Q., WANG R., LI T., ZHOU J.P., CHANG G., ZHAO N., et al.: Reduced soluble RAGE is associated with disease severity of axonal Guillain-Barré syndrome. Sci. Rep., 6: 21890, 2016.

9- NAJAR M., FAYYAD-KAZAN M., RAICEVIC G., FAYYAD-KAZAN H., MEULEMAN N., BRON D., et al.: Advanced Glycation End-Products-, C-Type Lectinand Cysteinyl/Leukotriene-Receptors in Distinct Mesenchymal Stromal Cell Populations: Differential Transcriptional Profiles in Response to Inflammation. Cell J., 20 (2): $250-8,2018$

10-MOKBEL A., RASHID L. and AL-HARIZY R.: Decreased level of soluble receptors of advanced glycated end products (sRAGE) and glycine 82 serine (G82S) polymorphism in Egyptian patients with RA. The Egyptian Rheumatologist, 33: 53-60, 2011.

11- ROWAN S., BEJARANO E. and TAYLOR A.: Mechanistic targeting of advanced glycation end-products in age-related diseases. Biochim. Biophys. Acta Mol. Basis Dis., 1864 (12): 3631-43, 2008.

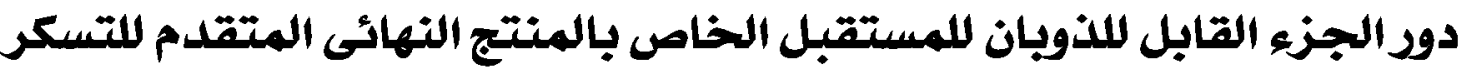

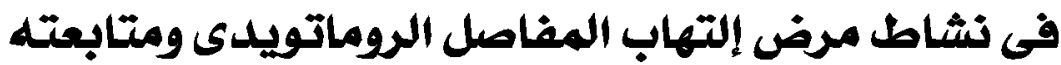

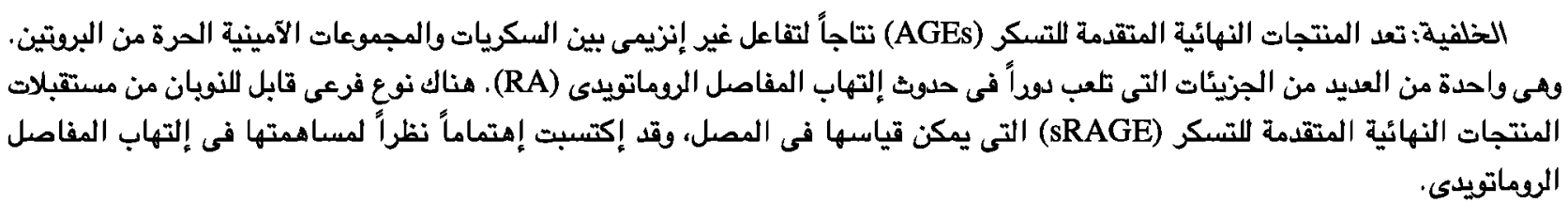

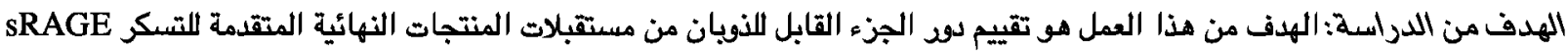

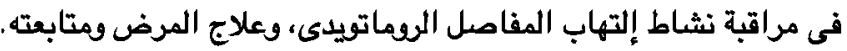

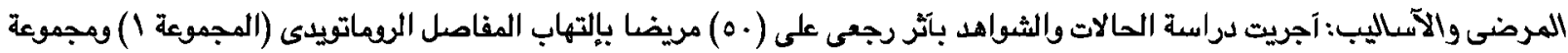

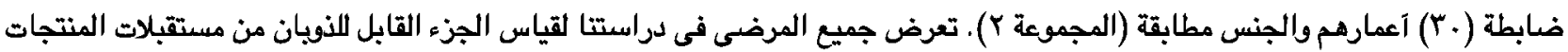

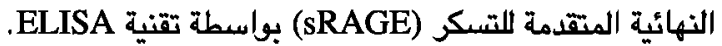

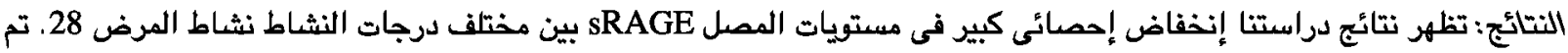

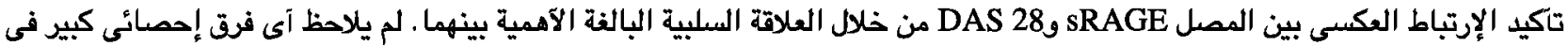

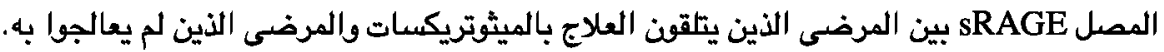

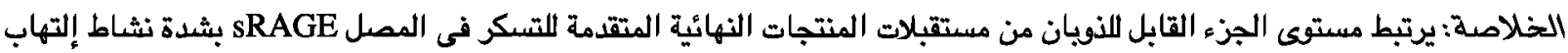
المفاصل الروماتويدى مع إنخفاض مستوياته فى المصل فى المرض النشط. لمن دراستتا لم تتمكن من آن تثبت دوده فى متابعة علاج المرض. 